\title{
Parthenocarpy in Lonicera caerulea (Caprifoliaceae)
}

\author{
Huo Junwei ${ }^{1 *}$, and Irina G. Boyarskikh ${ }^{2}$ \\ ${ }^{1}$ College of Horticulture, Northeast Agricultural University, Harbin, China \\ ${ }^{2}$ Central Siberian Botanical Garden of the SB RAS, Zolotodolinskaya Str., 101, Novosibirsk, 630090, \\ Russia
}

\begin{abstract}
The properties of fruits produced by the blue honeysuckle hybrid cultivar Berel under different pollination conditions while grown in the north-east of China and in West Siberia were examined. The frequent incidence of leaves chlorosis and partenocarphy of Lonicera caerulea L. was recorded for the first time.
\end{abstract}

\section{Introduction}

Presently plant material is the major source for producing more than one third of all medicines and most of the biologically active food supplements worldwide. Numerous studies both in Russia and abroad have focused to find and use new nonconventional plant sources of biologically active substances for pharmacology and functional nutrition. Blue honeysuckle (Lonicera caerulea L. s. 1.) is a very valuable berry-producing species. Its fruits and leaves can be used as a source of natural antioxidants, dyes, as well as functional food components [1,2], being an important food supplement for preventing certain chronic diseases, like cancer, diabetes, cardiovascular and neurodegenerative diseases [1]. So in the last decades many countries with temperate climate intensified their efforts to introduce blue honeysuckle into culture. Despite this great research interest to L. caerulea, the reproductive biology of the species has received little attention so far. The lack of knowledge about the details of pollination and fertilization leads to serious mistakes while implementing programs of broad scale species introduction into culture.

The cultivars developed in Russia are most often used for breeding programs and agricultural production. The survey of the breeding centers of the Heilongjiang province (China) that we carried out in 2014, showed that only one cultivar of the Russian selection, namely Berel, had been used for large scale production. The cultivar attracted attention in collection plantations of some of the farms in the north-east of China due to the beneficial combination of a number of agriculturally valuable traits. The cultivar was obtained as a result of pollinating the selected high quality form L caerulea subsp. altaica (Ball.) originated in the Rudny Altai region with the pollen mixture from L. caerulea subsp. kamtschatica (Pojark) of the Kamchatka origin (such cultivars as Goluboye vereteno in Russian, i.e. Blue Spindle; Sinyaya ptitsa, or Blue Bird; and Lazurnaya, or Azure). The hybrid is characterized by a combination of outstanding agriculturally beneficial traits, such as high productivity (up to $6 \mathrm{~kg}$ per

\footnotetext{
* Corresponding author: irina 2302@mail.ru
} 
plant), strong connection of rather big (up to $1.6 \mathrm{~g}$ ) fruits of good taste (4.3 sensory points), early start of fruit production (the third year after planting) and very high content of biologically active polyphenol compounds $[2,3]$.

The $L$. caerulea is known to be a self-fruitless species, i.e. when pollinated with the same cultivar pollen the fruits do not set up at all or set up in a small number of small seedless fruits $[4,5]$. Single cultivar plantations lead to practically complete fruitlessness of plants. At the same time the reports from one of the farms in the Gunhe settlement (Muling district, Heilongjiangb province) showed yields from the single cultivar Berel plantation of the blue honeysuckle, which contradicted with the data about the L. caerulea self-fruition

So the aim of our work was to study the peculiarities of Berel cultivar fruition in different growing environments in Heilongjiangb province, China, and in Novosibirsk region, Russia.

\section{Materials and methods}

The honeysuckle berries for the study were collected in 2014 in China in the north-east of Heilongjiang province in Gunhe settlement in the Muling county in the foothills of Manchuria-Korean Mountains, in Wujimi settlement of the Shangzhi county and in the experimental station of the Northeast University (Harbin) in the forest-steppe zone. The data about blue honeysuckle fruits collected in 2000 and 2014 in Novosibirsk from the plant introduction experimental plantation of the Central Siberian Botanical Garden (CSBG) were used for comparison.

In the Gunhe plantation was established as a sole cultivar Berel one, whereas in Wujimi settlement two closely related cultivars Berel and Blue Bird were planted, and in the Northeast Agricultural University (Harbin, China), similar to the CSBG, the blue honeysuckle collection, besides Berel cultivar, embraced more than 100 varieties of different environmental and geographic provenances and genetic origin. The mean fruit mass (fresh), fruit length and width, seed production per fruit, as well as coefficient of variation (CV) of these properties, were determined.

\section{Results and their discussion}

The conducted survey of 1 ha of Berel cultivar plantation in the Gunhe settlement showed that 4-yrs old plants had quite high productivity of $0.3-0.4 \mathrm{~kg} / \mathrm{plant}$. The fruits collected from the plantation had no seeds, and their mass was 3 times less, as compared to the fruits collected of the same cultivar plantations in the same province, but in a different pollination environment; and 1.5 times less as compared to the fruits produced in the continental climate of Novosibirsk West Siberia (Table). Other L. caerulea cultivars on Gunhe plantation were absent. Locally several plants of the native species L. boczkarnikowae Plekh. (syn. L. regelyana Boczkarn.) were found. The species has a diploid set of chromosomes $(2 \mathrm{n}=18)$ [6]. These L. boczkarnikowae plants could not be productive pollinators for the Berel cultivar, as the latter has a tetraploid set of chromosomes $(2 n=36)$, and the setting of fruits under cross-pollination between di- and tetraploid blue honeysuckle cultivars is very low [7].

An earlier study conducted in Novosibirsk (West Siberia) for most of the studied $L$. caerulea s.l. cultivars revealed strong positive correlation $(0.73-0.98 \%, p<0,001)$ between fruit mass and the number of mature seeds Poorly developed seeds were found to have little effect on the fruit mass [8]. The prevailing setting of seedless fruits (parthenocarpy) 
was observed for the first time, as we could not find publications reporting the phenomenon for $L$. caerulea.

Table. Fruit properties of the Berel cultivar blue honeysuckle plants grown in different climatic conditions and pollination environments

\begin{tabular}{|c|c|c|c|c|c|c|c|c|c|c|c|c|}
\hline \multirow{2}{*}{$\begin{array}{l}\text { Location and } \\
\text { year of fruit } \\
\text { collection }\end{array}$} & \multicolumn{3}{|c|}{ Fruit length, cm } & \multicolumn{3}{|c|}{ Fruit width, cm } & \multicolumn{3}{|c|}{ Fruit mass, $\mathbf{g}$} & \multicolumn{3}{|c|}{$\begin{array}{c}\text { Number of seeds, } \\
\text { pcs }\end{array}$} \\
\hline & Mean & Rang & \begin{tabular}{|l|}
$\mathbf{C}$ \\
$\mathrm{V}$, \\
$\mathbf{\%}$ \\
\end{tabular} & Mean & Rang & $\begin{array}{c}\text { CV, } \\
\%\end{array}$ & Mean & $\begin{array}{c}\text { Rang } \\
\text { e }\end{array}$ & $\begin{array}{c}\text { CV, } \\
\%\end{array}$ & Mean & $\begin{array}{c}\text { Rang } \\
\text { e }\end{array}$ & $\begin{array}{l}\mathrm{CV}, \\
\%\end{array}$ \\
\hline $\begin{array}{l}\text { Novosibirsk, } \\
2014\end{array}$ & $\begin{array}{c}1.5 \pm 0 . \\
05\end{array}$ & $\begin{array}{c}1.0- \\
1.9\end{array}$ & 14 & $\begin{array}{c}0.8 \pm 0 . \\
03\end{array}$ & $\begin{array}{c}0.6- \\
1.0\end{array}$ & 15 & $\begin{array}{c}0.6 \pm 0 . \\
03\end{array}$ & $\begin{array}{c}0.3- \\
0.8\end{array}$ & 23 & $\begin{array}{c}14.5 \pm 1 \\
.6\end{array}$ & $3-23$ & 124 \\
\hline $\begin{array}{l}\text { Novosibirsk, } \\
2000\end{array}$ & $\begin{array}{c}1.6 \pm 0 . \\
68\end{array}$ & $\begin{array}{c}1.1- \\
2.1 \\
\end{array}$ & 21 & $\begin{array}{c}1.0 \pm 0 . \\
47\end{array}$ & $\begin{array}{c}0.6- \\
1.4 \\
\end{array}$ & 24 & $\begin{array}{c}0.6 \pm 0 . \\
02 \\
\end{array}$ & $\begin{array}{c}0.2- \\
1.1 \\
\end{array}$ & 43 & \begin{tabular}{|c|}
$4.5 \pm 0$. \\
8 \\
\end{tabular} & $1-14$ & 89 \\
\hline Harbin, 2014 & $\begin{array}{c}1.8 \pm 0 . \\
04\end{array}$ & $\begin{array}{l}1.4- \\
2.4 \\
\end{array}$ & 15 & $\begin{array}{c}1.3 \pm 0 . \\
05\end{array}$ & $\begin{array}{l}0.8- \\
1.8 \\
\end{array}$ & 22 & $\begin{array}{c}1.3 \pm 0 . \\
06\end{array}$ & $\begin{array}{c}0.8- \\
1.7 \\
\end{array}$ & 21 & \begin{tabular}{|c|}
$14.3 \pm 1$ \\
.0 \\
\end{tabular} & $4-25$ & 75 \\
\hline Wujimi, 2014 & $\begin{array}{c}1.9 \pm 0 . \\
06\end{array}$ & $\begin{array}{l}1.5- \\
2.5 \\
\end{array}$ & 13 & $\begin{array}{c}1.2 \pm 0 . \\
07\end{array}$ & $\begin{array}{l}0.8- \\
1.7 \\
\end{array}$ & 21 & $\begin{array}{c}1.2 \pm 0 . \\
06\end{array}$ & $\begin{array}{c}0.8- \\
1.6 \\
\end{array}$ & 20 & \begin{tabular}{|c|}
$2.5 \pm 0$. \\
3 \\
\end{tabular} & $1-4$ & 46 \\
\hline Gunhe, 2014 & $\begin{array}{c}1.5 \pm 0 . \\
02\end{array}$ & $\begin{array}{c}1.2- \\
1.7\end{array}$ & 8 & $\begin{array}{c}0.8 \pm 0 . \\
02\end{array}$ & $\begin{array}{c}0.6- \\
1.1\end{array}$ & 14 & $\begin{array}{c}0.4 \pm 0 . \\
02\end{array}$ & \begin{tabular}{|c|}
$0.2-$ \\
0.5
\end{tabular} & 20 & 0 & 0 & \\
\hline
\end{tabular}

The phenomenon of parthenocarpy, i.e. development of fruits without fertilization, can be observed under the influence of phytohormones or different chemical reagents that, as a rule, induce the biosynthesis of such hormones. The processes of seed development and fruit growth are well known to be intimately related, synchronized and phytohormonally regulated. Auxin plays the most important role in fruit development regulation. The exogenous treatment of non-pollinated flowers of various cultivated plants by natural or artificial auxins initiates fruit growth. So such hormones can substitute the signals produced

by proper pollination and fertilization. This hypothesis is confirmed by the increased levels of auxins in flower organs after ovule fertilization. Molecular analyses confirmed the important role of auxin signals in triggering and coordination of the transition from a flower into a fruit. The embryo growth is supposed to be blocked by other hormones until the pollination, and auxin participated in depressing embryo growth after fertilization [9].

In the attempt to find the cause of the parthenocarpy in Gunhe plantation, our attention was drawn to the high incidence of inter-vein chlorosis of young leaves, which evidenced the inadequate mineral nutrition on this plantation. However, the plants of the native $L$. boczkarnikowae species that also scarcely grew on the same plantation displayed no chlorosis. Thus the native blue honeysuckle species seems to be well adapted to the specifics of macro- and trace elements soil composition in the area. The aberrant mineral nutrition is known to enhance phytohormones synthesis, in particular in saline soil sites, under drought, etc. [10]. It seems very likely that in L. caerulea plants there exists a relationship between physiological changes, causing chlorosis, and the frequent incidence of parthenocarpy.

\section{Conclusion}

The results of the conducted study showed that in the north-east of China (Muling county, Heilongjiang province) in the sole-cultivar L. caerulea plantations the seedless fruit setting and development (parthenocarpy) takes place. The changed phytohormones synthesis due to inadequate plant mineral nutrition may be the probable cause for the parthenocarpy. 
The study is carried out according to of the state assignment of the Central Siberian Botanical Garden of the Siberian Branch of the Russian Academy of Sciences, state registration no. AAAA-A17117012610053-9 and applying bioresource scientific "Collection of Living Plants in Open and Closed Ground" USU 440534.

\section{References}

1. H.P.V. Rupasinghe, N. Arumuggam, M. Amararathna, A.B.K.H. De Silva J. Funct. Foods, 44, 24-39 (2018)

2. I.G. Boyarskikh, YU.V. Yushkova, E.I. Chernyak, S.V. Morozov, Bulletin of altai state agrarian university, 3, 39-46 (2011)

3. Z.P. Zholobova, G.A. Prishchepina, Honeysuckle: History, state and prospects of culture in Siberia (Barnaul, 2003)

4. M.N. Plekhanova, Byul. VIR, 126, 53-58 (1982)

5. I.G. Boyarskikh, Agricultural biology, 52, 1, 200-210 (2017)

6. M.N. Plekhanova, Bulletin of applied botany, genetics and plant breeding, 162, 59-70 (2006)

7. T. Miyashita, Y. Hoshino, Euphytica, 201, 1, 15-27 (2015)

8. I.G. Boyarskih, Biological features of representatives of Lonicera caerulea L. s.l., Avtoref. kand. dis. (Novosibirsk, 2004)

9. T. Pandolfini, Nutrients, 1, 168-177 (2009)

10. D.S. Veselov, S.Yu. Veselov, L.B. Vysockaya, G.R. Kuboyarova, R.G. Farhutdinov, Plant hormones: concentration regulation, association with growth and water metabolism (Moscow, Nauka, 2007) 